\title{
Nitro-fatty acids: novel anti-inflammatory lipid mediators
}

\author{
H. Rubbo \\ Department of Biochemistry and Center for Radical and Biomedical Research, Faculty of Medicine, \\ University of the Republic, Montevideo, Uruguay
}

\begin{abstract}
Nitro-fatty acids are formed and detected in human plasma, cell membranes, and tissue, modulating metabolic as well as inflammatory signaling pathways. Here we discuss the mechanisms of nitro-fatty acid formation as well as their key chemical and biochemical properties. The electrophilic properties of nitro-fatty acids to activate anti-inflammatory signaling pathways are discussed in detail. A critical issue is the influence of nitroarachidonic acid on prostaglandin endoperoxide $\mathrm{H}$ synthases, redirecting arachidonic acid metabolism and signaling. We also analyze in vivo data supporting nitro-fatty acids as promising pharmacological tools to prevent inflammatory diseases.
\end{abstract}

Key words: Nitro-fatty acids; Antioxidants; Nitric oxide; Inflammation

\section{Introduction}

Nitric oxide ("NO)-derived species (NOx) react with unsaturated fatty acids to yield a variety of oxidized and nitrated products (1). In particular, nitroalkenes $\left(\mathrm{NO}_{2}-\mathrm{FA}\right)$ have been detected, identified, and quantified in plasma as well as in cell membranes and tissue $(2,3)$. The mechanisms of fatty acid nitration in vivo remain unknown, with suggested pathways including reactions of unsaturated fatty acids with secondary products of ${ }^{\mathrm{NO}}$ oxidation such as nitrogen dioxide $\left({ }^{\circ} \mathrm{NO}_{2}\right)$, nitrite $\left(\mathrm{NO}_{2}{ }^{-}\right)$, and peroxynitrite (ONOO${ }^{-}$; Figure 1). Nitrogen dioxide can be formed from ' $\mathrm{NO}$ autoxidation (4). Alternatively, ${ }^{\circ} \mathrm{NO}_{2}$ can be formed from $\mathrm{NO}_{2}{ }^{-}$, since $\mathrm{NO}_{2}{ }^{-}$is present in physiological fluids at high concentrations $(5,6)$. Moreover, $\mathrm{NO}_{2}^{-}$should be exposed to low $\mathrm{pH}$ in the gastric compartment as well as in phagocytic lysosomes to generate $\mathrm{NO}_{2}$; indeed, the human stomach is a source of $\mathrm{NO}$ and bioactive nitrogen oxides from precursors present in food and saliva (6). A critical step is the protonation of $\mathrm{NO}_{2}^{-}$in the gastric lumen, thereby forming nitrous acid $\left(\mathrm{HNO}_{2}\right)$, which can also form ${ }^{\circ} \mathrm{NO},{ }^{\circ} \mathrm{NO}_{2}$, and other nitrogen oxides (6). An additional lipid nitration mechanism involves peroxynitrite. Peroxynitrite anion $\left(\mathrm{ONOO}^{-}\right)$and peroxynitrous acid $(\mathrm{ONOOH})$ are potent one- and two-electron oxidants that can react with unsaturated fatty acids (4). Homolysis of $\mathrm{ONOOH}$ yields ${ }^{\circ} \mathrm{NO}_{2}$ and hydroxyl radical $\left({ }^{\circ} \mathrm{OH}\right)$. In fact, ONOO', $\mathrm{ONOOH}$, and/or their derived radicals have been observed to readily diffuse through membranes to mediate fatty acid oxidation and nitration (1,7-10). Several reports support $\mathrm{NO}_{2}$-FA formation in vivo (11-14). In fact, nitroalkenes are present endogenously as free, esterified, and nucleophilicadducted species (12), and although reports about in vivo concentrations have changed from the micromolar (2) to the picomolar range (15) in the past few years, their presence has been shown to be greatly increased in inflammatory models $(12,14,16)$. During macrophage activation by an inflammatory stimulus, one of the major esterified lipid components, cholesteryl linoleate (CL), becomes nitrated at the fatty acid moiety (12). The formation of cholesteryl nitrolinoleate $\left(\mathrm{NO}_{2}-\mathrm{CL}\right)$ by activated macrophages is prevented by nitric oxide synthase (NOS) inhibitors, supporting the contribution of 'NOderived species toward CL nitration. More recently, it has been demonstrated that $\mathrm{NO}_{2}-\mathrm{FA}$ is both present and formed in mitochondria from cardiac ischemia/reperfusion (13) or ischemic preconditioned (14) hearts.

\section{Nitric oxide and arachidonic acid signaling are linked through nitro-fatty acids}

It has been well established that arachidonic acid (AA) signaling cascades and $\mathrm{NO}$ pathways are intrinsically related (17). Nitration of AA yields a nitroalkene, nitroarachidonic acid $\left(\mathrm{NO}_{2}-\mathrm{AA}\right)$. In activated macrophages, 


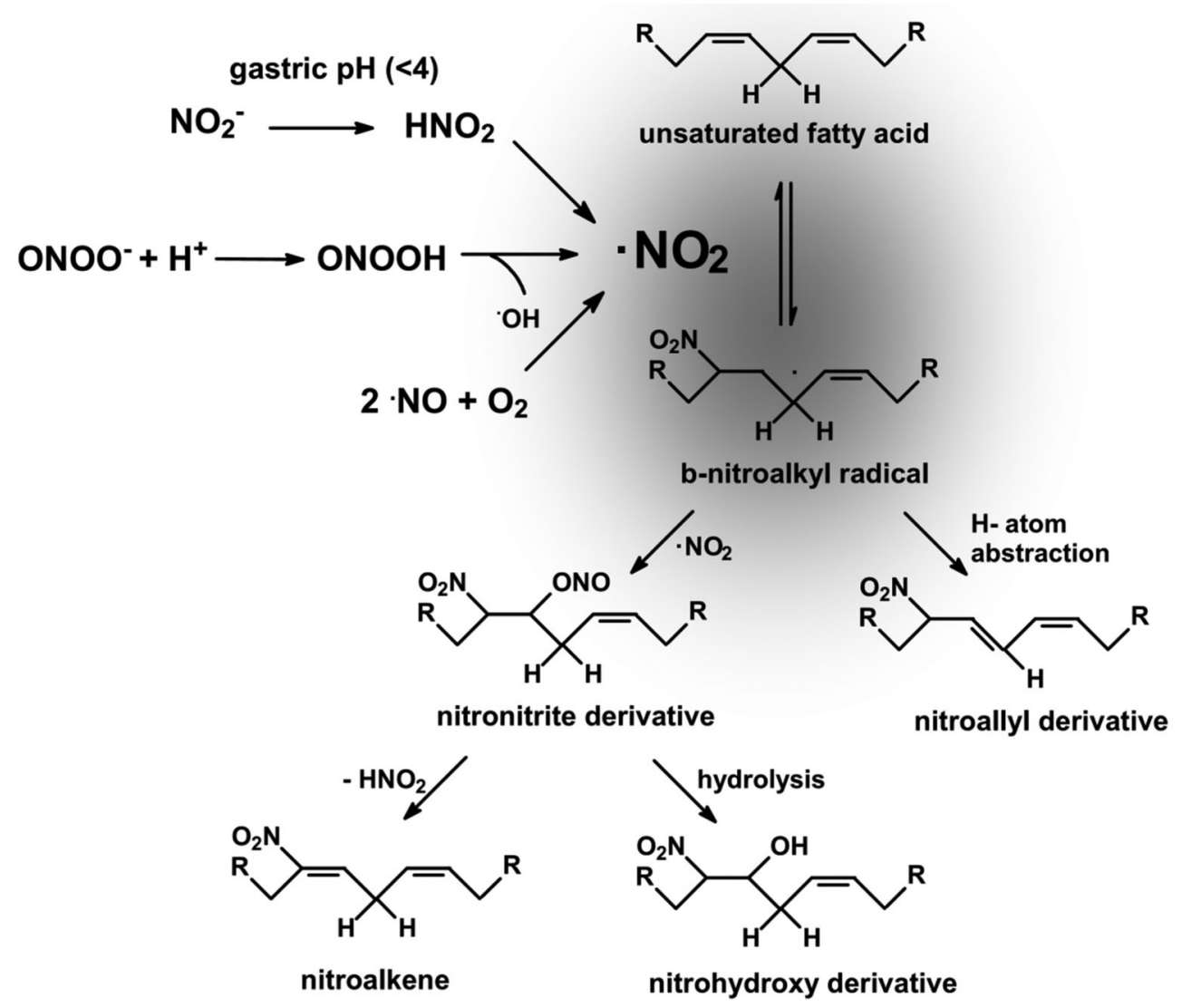

Figure 1. Mechanisms of unsaturated fatty acid nitration. Nitrogen dioxide can be formed by at least three major biologically relevant mechanisms (see text) and react with unsaturated fatty acids to preferentially form (at low oxygen tensions) nitro-alkenes (nitro group bonded at the double bond) and nitro-allyl derivatives (nitro group bonded at a single bond). $\mathrm{NO}_{2}-\mathrm{FA}$ alkylates susceptible thiols of multiple transcriptional regulatory proteins, affecting downstream gene expression and the metabolic and inflammatory responses under their regulation.

$\mathrm{NO}_{2}-\mathrm{AA}$ exerts a protective anti-inflammatory action, diminishing NOS-2 expression and secretion of proinflammatory cytokines (18). Downregulation of NOS-2 by nitroalkenes should contribute to the physiological shutdown of inflammatory responses in macrophages. Both $\mathrm{NO}_{2}-\mathrm{AA}$ and its methylated form (Met6- $\mathrm{NO}_{2}-\mathrm{AA}$ ) increased cGMP levels in treated endothelial cells, suggesting that guanylate cyclase was activated directly or via 'NO/NOlike species (19). Nitroalkenes react with nucleophilic residues in proteins (16); they are potent electrophiles, and the addition of a nitro group $\left(-\mathrm{NO}_{2}\right)$ to a double bond at the carbon chain of the unsaturated fatty acids leads to an alkenyl nitroconfiguration with electrophilic reactivity of the $\beta$-carbon adjacent to the nitro-bonded carbon. Through Michael addition reactions, nitroalkenes can react with nucleophiles (i.e., Cys or His residues), yielding a new carbon-carbon or carbon-heteroatom bond framework $(20-22)$. Biochemical studies reveal that $\mathrm{NO}_{2}-\mathrm{FA}$ rapidly and reversibly undergoes Michael addition with thiols and, to a lesser extent, primary and secondary amines (20-22).
In contrast to other lipid-derived electrophiles, nitroalkylation of Cys and His is reversible $(16,20,22)$. Through this mechanism, $\mathrm{NO}_{2}-\mathrm{FA}$ alkylate susceptible thiols of multiple transcriptional regulatory proteins affect downstream gene expression and the metabolic and inflammatory responses under their regulation.

\section{Nitroalkene activation of anti-inflammatory signaling pathways}

Under physiological conditions, intracellular levels of glutathione can detoxify $\mathrm{NOx}$, favoring $\mathrm{NO}_{2}-\mathrm{FA}$ formation to activate anti-inflammatory signaling pathways (Figure 2). When high production rates of NOx such as peroxynitrite occur related to inflammation, antioxidant mechanisms are compromised; then, protein tyrosine nitration (and oxidation) increase and participate in events such as mitochondrial cytochrome $c$ release and apoptosis (Figure 2). Even under this unfavorable biochemical scenario, $\mathrm{NO}_{2}-\mathrm{FA}$ may serve as a cytoprotective agent, 


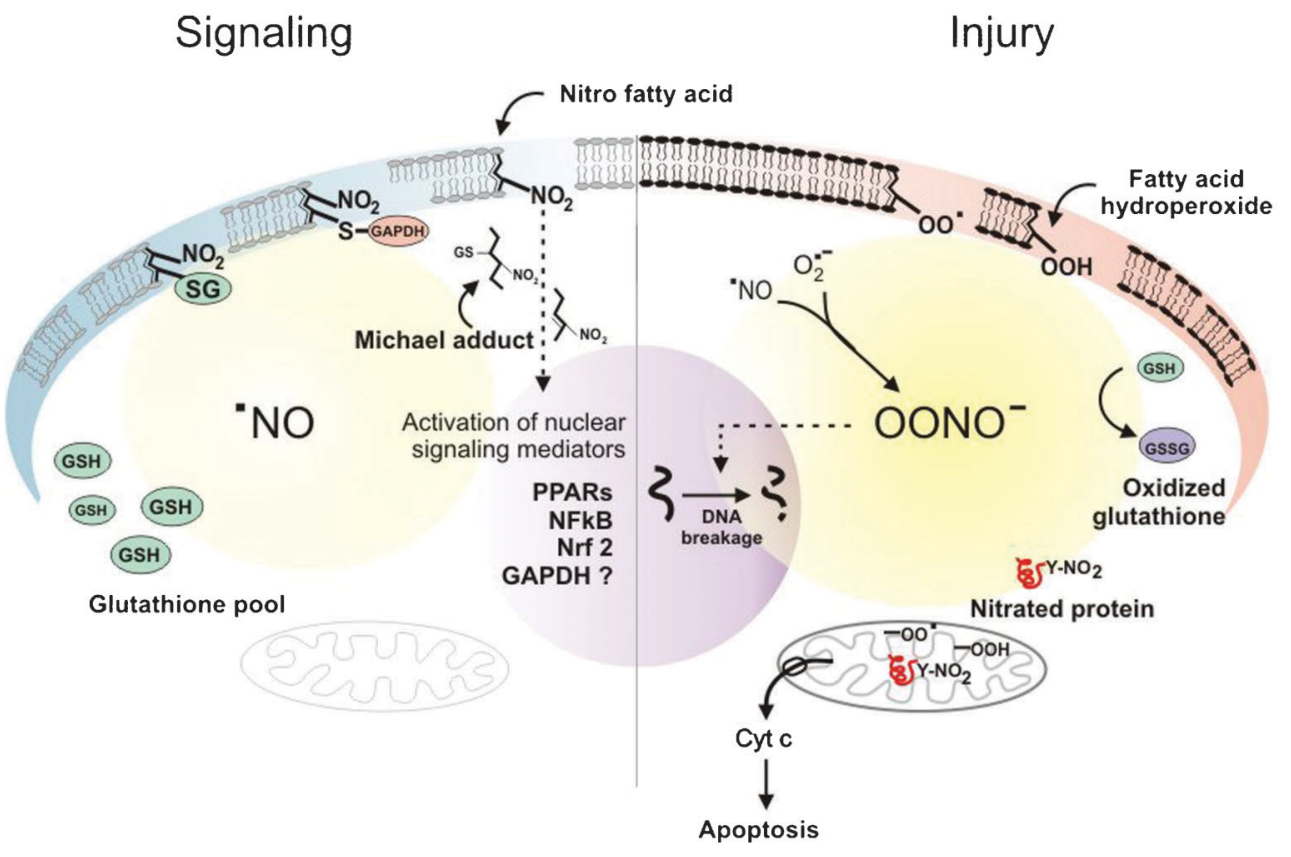

Figure 2. Nitroalkene-activation of anti-inflammatory signaling pathways. On the left side of the scheme, the signaling role of nitroalkenes and nitroalkene thiol adducts on transcription factors is indicated in a cell with normal levels of GSH. On the right side, cytotoxic events predominate as a result of an increase in NOx, leading to pro-oxidant pathways that include GSH depletion, protein tyrosine nitration and lipid oxidation, triggering apoptotic cascades. Adapted from Ref. 47, with permission.

partially counteracting the proinflammatory effects of oxidant exposure, thus inhibiting the propagation of lipid oxidation and protein nitration, in part by attenuating the oxidant-dependent inflammatory response. Key antiinflammatory mechanisms include the following.

\section{Peroxisome proliferator-activated receptor (PPAR) activation}

The transcriptional factor PPAR has been found to serve as a nuclear receptor capable of selectively binding $\mathrm{NO}_{2}$-FA. Nitroalkenes are able to potently regulate the expression of multiple PPAR target genes (23-25). The effects of $\mathrm{NO}_{2}$-FA on full-length PPAR were then tested in transfection assays using a PPAR $\gamma$ response reporter, where nitroalkenes potently activated all PPAR subtypes, having a stronger activity on PPAR $\gamma$ than PPAR $\alpha$ and PPAR $\beta / \delta$ (11). This is of significance since PPAR $\gamma$ has been associated with anti-inflammatory actions such as modulation of expression of several proinflammatory cytokines and chemokines in activated macrophages.

\section{Inhibition of nuclear factor-kappa B (NF-кB)}

Various mechanisms have been proposed to explain the protective actions exerted by nitroalkenes. One of them involves the inhibition of NF- $\mathrm{KB}$ translocation to the nucleus $(11,13)$. In fact, NF- $\kappa B$ plays an important role during inflammatory responses, regulating genes that encode proinflammatory cytokines. Nitroalkenes can inhibit lipopolysaccharide-induced secretion of proinflammatory cytokines in macrophages [e.g., interleukin-6, tumor necrosis factor- $\alpha$, and monocyte chemoattractant protein 1 (MCP-1)]. These observed effects resulted from the covalent alkylation of recombinant NF- $\mathrm{B}$ p 65 protein in vitro and from a similar reaction with the $\mathrm{p} 65$ subunit in

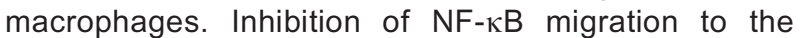
nucleus inhibited DNA binding activity and repressed NF-кB-dependent target gene expression (11).

\section{Induction of hemoxygenase-1 (HO-1)}

$\mathrm{HO}-1$ catalyzes the oxidative degradation of heme to biliverdin, exerting anti-oxidant and anti-inflammatory actions. Induction of $\mathrm{HO}-1$ is an endogenous cytoprotective pathway triggered by a variety of stress-related signals and electrophilic species. Nitroalkenes induce $\mathrm{HO}-1$ expression in endothelial cells (26), RAW264.7 (11), and J774.1 macrophages (12) by a PPAR $\gamma$-independent mechanism as well as both "NO-dependent and $\mathrm{NO}$-independent mechanisms (26). Considering the vascular protective effects of $\mathrm{HO}-1$ expression, induction of $\mathrm{HO}-1$ represents a key novel cell-signaling action of nitroalkenes.

Activation of nuclear factor E2-related factor 2 (Nrf2)

Nrf2 is a mediator of antioxidant and phase II detoxifying enzyme expression (27-29). Nrf2 is a transcription factor that is in an inactive form in the cytosol due to the activity of Kelch-like ECH-associated protein 1 
(Keap1). When activated Nrf2 migrates to the nucleus, it binds as a heterodimer to the antioxidant response element (ARE) in DNA, activating the expression of phase 2 enzymes (29). Potential activators for Nrf2 include lipid electrophiles that react with reactive Keap1 thiols, dissociating Nrf2 from ubiquitin E3 ligase complex and facilitating nuclear accumulation and downstream effects on gene transcription (29). Keap1 is highly reactive to nitroalkylation because it constitutes a cysteine-rich protein (27-29). Diverse functional studies using Keap1 mutants showed that Cys ${ }^{151}$ is an electrophile sensor residue whose adduction causes the dissociation of Keap1 from Cul3, preventing Nrf2 proteosomal degradation and allowing the activation of its target genes via binding to AREs (30-32). Nitro-fatty acids are Cys ${ }^{151}$. independent Nrf2 activators, as Keap1 Cys ${ }^{151}$ mutants remain unaffected by nitroalkenes, enhancing, instead of diminishing, the binding of Keap1 with Cul3 (33). Like $\mathrm{HO}-1$, Nrf2 activation protects various cell types against oxidative stress. In this way, vascular smooth muscle cell (VSMC) proliferation is inhibited by physiological levels of nitroalkenes (34). The signaling pathway that participates in this action involves the Nrf2/ARE system. During VSMC inhibition of proliferation, Nrf2 nuclear translocation is enhanced by $\mathrm{NO}_{2}-\mathrm{FA}$, suggesting that this signaling cascade is also involved in the observed anti-inflammatory actions of nitroalkenes (34). The role of $\mathrm{NO}_{2}-\mathrm{FA}$ on the Nrf2 pathway has also been explored in human aortic endothelial cells (35). The expression of Nrf2-dependent genes, including $\mathrm{HO}-1$ and glutamate cysteine ligase modifier subunit, was significantly stimulated by $\mathrm{NO}_{2}-\mathrm{FA}$; however, array analyses showed that the majority of $\mathrm{NO}_{2}$-FA-regulated genes were regulated by Nrf2independent pathways. More in depth studies demonstrated that the heat shock response is the major pathway activated by $\mathrm{NO}_{2}-\mathrm{FA}$ (35). Regulation of the heat shock response is a novel anti-inflammatory and cytoprotective action of $\mathrm{NO}_{2}-\mathrm{FA}$ in addition to the other protective cell signaling functions reported for nitroalkenes.

\section{Modulation of prostaglandin endoperoxide $\mathbf{H}$ synthase (PGHS)}

PGHS is a key enzyme of AA metabolism catalyzing the formation of prostaglandin $\mathrm{H}_{2}$ (36-38). Two isoforms of PGHS (PGHS-1 and PGHS-2) are found in mammalian tissues. PGHS-1 is constitutively expressed, whereas PGHS-2 is an inducible enzyme. Both isoforms are of pharmacological importance because they are targets for nonsteroidal anti-inflammatory drugs (39). Prostaglandin $\mathrm{H}_{2}$ formation by PGHS catalysis involves two separate reactions at different active sites (36-38). The first is oxidation of $A A$ by the cyclooxygenase reaction to yield prostaglandin $G_{2}$, where two molecules of oxygen are added to $A A$, and the second is reduction of the hydroperoxyl group at $\mathrm{C} 15$ by the peroxidase reaction, yielding prostaglandin $\mathrm{H}_{2}(37,38,40)$. We have recently evaluated the interaction of the nitrated derivative of $A A$ with PGHS (41). Kinetic analysis showed that the inhibition of peroxidase activity exerted by $\mathrm{NO}_{2}-\mathrm{AA}$ was time- and concentration-dependent in both PGHS-1 and PGHS-2, suggesting a two-step mechanism of inactivation: an initial reversible binding followed by a practically irreversible event leading to enzyme inactivation. Inactivation was associated with an irreversible disruption of heme binding to the protein. The observed effects for $\mathrm{NO}_{2}-\mathrm{AA}$ were selective, since other nitroalkenes tested were unable to inhibit enzyme activity. In activated human platelets, $\mathrm{NO}_{2}-\mathrm{AA}$ significantly decreased PGHS-1dependent thromboxane $B_{2}$ formation in parallel with a decrease in platelet aggregation, thus confirming the biological relevance of this novel inhibitory pathway (41). These anti-platelet effects were CGMP-independent and did not involve $\mathrm{Ca}^{2+}$-store-dependent mobilization, providing a possible novel mechanism for platelet regulation in vivo. Signaling downstream of protein kinase C (PKC), such as $\alpha$-granule secretion and extracellular signalregulated kinase 2 activation, was strongly inhibited by $\mathrm{NO}_{2}$-AA (42). Inhibition of $\mathrm{PKC} \alpha$ translocation to the plasma membrane represents a potential mechanism for platelet regulation in vivo.

\section{Modulation of NADPH oxidase (NOX)}

A novel additional mechanism by which $\mathrm{NO}_{2}-\mathrm{AA}$ may have anti-inflammatory actions is the regulation of superoxide radical $\left(\mathrm{O}_{2}^{-}\right)$production via NOX isoforms. In fact, nitroalkenes may alter the formation of $\mathrm{O}_{2} \overrightarrow{ }$ during macrophage activation by modulating phagocytic NOX-2. Recent data show that $\mathrm{NO}_{2}-\mathrm{AA}$ inhibits NOX-2-mediated $\mathrm{O}_{2}{ }^{-}$production in activated macrophages (43). The mechanism involves prevention of migration of cytosolic subunits to the membrane, thus inhibiting correct assembly of the active enzyme. This inhibitory role of nitroalkenes observed during macrophage activation could facilitate the resolution of inflammation.

\section{Therapeutic potential}

While the biochemical mechanisms leading to lipid nitration are under active investigation, there is unambiguous evidence of their formation in vivo as well as their increase during inflammatory conditions. Thus, it is possible that, at the levels expected to be found in vivo during chronic inflammatory conditions, nitrated lipids may serve as anti-oxidant and anti-inflammatory agents, partially counteracting the proinflammatory effects of oxidant exposure. There are several reports using $\mathrm{NO}_{2}-$ FA as pharmacological modulators of inflammationrelated diseases in animal models $(13,14,44)$. Nitro-fatty acid subcutaneous administration to angiotensin II-treated mice significantly lowered the increase in blood pressure as well as the contractile responses through $\mathrm{NO}_{2}-\mathrm{FA}$ binding to the AT1R, modulating intracellular signaling 
cascades (inositol-1,4,5-trisphosphate and calcium mobilization) (44). These results show that $\mathrm{NO}_{2}-\mathrm{FA}$ diminishes the pressor response to angiotensin II, inhibiting AT1Rdependent vasoconstriction and suggesting that $\mathrm{NO}_{2}-\mathrm{FA}$ can be a pharmacologically relevant modulator of hypertension (44). $\mathrm{NO}_{2}-\mathrm{FA}$ were also tested in $\mathrm{C} 57 \mathrm{BL} / 6$ mice subjected to coronary artery ligation followed by 30 min reperfusion $(\mathrm{I} / \mathrm{R})$. When administered exogenously during an ischemic episode, $\mathrm{NO}_{2}-\mathrm{FA}$ exerted protection against $\mathrm{I} / \mathrm{R}$ injury, reducing the infarct size as well as preserving the left ventricular function (13). In an animal model of atherosclerosis, subcutaneous administration of $\mathrm{NO}_{2}$-FA potently reduced atherosclerotic lesion formation (45). More recently, it has been demonstrated that acute administration of $\mathrm{NO}_{2}-\mathrm{FA}$ is effective to reduce vascular inflammation in vivo (46). The mechanism involves a

\section{References}

1. Rubbo H, Radi R, Trujillo M, Telleri R, Kalyanaraman B, Barnes $S$, et al. Nitric oxide regulation of superoxide and peroxynitrite-dependent lipid peroxidation. Formation of novel nitrogen-containing oxidized lipid derivatives. J Biol Chem 1994; 269: 26066-26075.

2. Baker PR, Lin Y, Schopfer FJ, Woodcock SR, Groeger AL, Batthyany $C$, et al. Fatty acid transduction of nitric oxide signaling: multiple nitrated unsaturated fatty acid derivatives exist in human blood and urine and serve as endogenous peroxisome proliferator-activated receptor ligands. J Biol Chem 2005; 280: 42464-42475, doi: 10.1074/jbc.M504212200.

3. Lima ES, Di Mascio P, Rubbo H, Abdalla DS. Characterization of linoleic acid nitration in human blood plasma by mass spectrometry. Biochemistry 2002; 41: 10717-10722, doi: 10.1021/bi025504j.

4. Radi R, Denicola A, Alvarez B, Ferrer G, Rubbo H. The biological chemistry of peroxynitrite. In: Ignarro LJ (Editor), Nitric oxide biology and pathobiology. San Diego: Academic Press; 2000. p 57-82.

5. Pannala AS, Mani AR, Spencer JP, Skinner V, Bruckdorfer $\mathrm{KR}$, Moore KP, et al. The effect of dietary nitrate on salivary, plasma, and urinary nitrate metabolism in humans. Free Radic Biol Med 2003; 34: 576-584, doi: 10.1016/S08915849(02)01353-9.

6. Lundberg JO, Weitzberg E. Biology of nitrogen oxides in the gastrointestinal tract. Gut 2013; 62: 616-629, doi: 10.1136/ gutjnl-2011-301649.

7. Radi R, Beckman JS, Bush KM, Freeman BA. Peroxynitriteinduced membrane lipid peroxidation: the cytotoxic potential of superoxide and nitric oxide. Arch Biochem Biophys 1991; 288: 481-487, doi: 10.1016/0003-9861(91)90224-7.

8. Rubbo $H$, Batthyány $C$, Freeman $B A$, Radi R, Denicola A. Nitric oxide diffusion across low density lipoprotein and inhibition of lipid oxidation-dependent chemiluminescence. Nitric Oxide 1998; 2: 117.

9. Botti $\mathrm{H}$, Trostchansky A, Batthyany $\mathrm{C}$, Rubbo H. Reactivity of peroxynitrite and nitric oxide with LDL. IUBMB Life 2005; 57: 407-412, doi: 10.1080/15216540500137701.

10. Khairutdinov RF, Coddington JW, Hurst JK. Permeation of phospholipid membranes by peroxynitrite. Biochemistry direct role for $\mathrm{NO}_{2}-\mathrm{FA}$ in the disruption of the Toll-like receptor 4 signaling complex in lipid rafts, leading to resolution of proinflammatory activation of $N F-\kappa B$ in the vasculature.

Although beneficial effects of $\mathrm{NO}_{2}-\mathrm{FA}$ have been clearly demonstrated in different in vivo models, there are still no reports evaluating the potential toxicity that this compound could exert when administered for longer periods of time. Further study is necessary to determine whether $\mathrm{NO}_{2}-\mathrm{FA}$ supplementation would exert novel anti-inflammatory and tissue protective actions in human disease.

\section{Acknowledgments}

Research supported by grants from ICGEB (Italy) and CSIC (Uruguay).

2000; 39: 14238-14249, doi: 10.1021/bi001270x.

11. Cui T, Schopfer FJ, Zhang J, Chen K, Ichikawa T, Baker PR, et al. Nitrated fatty acids: Endogenous anti-inflammatory signaling mediators. J Biol Chem 2006; 281: 35686-35698, doi: 10.1074/jbc.M603357200.

12. Ferreira AM, Ferrari MI, Trostchansky A, Batthyany C, Souza JM, Alvarez MN, et al. Macrophage activation induces formation of the anti-inflammatory lipid cholesteryl-nitrolinoleate. Biochem J 2009; 417: 223-234, doi: 10.1042/BJ20080701.

13. Rudolph V, Rudolph TK, Schopfer FJ, Bonacci G, Woodcock SR, Cole MP, et al. Endogenous generation and protective effects of nitro-fatty acids in a murine model of focal cardiac ischaemia and reperfusion. Cardiovasc Res 2010; 85: 155-166, doi: 10.1093/cvr/cvp275.

14. Nadtochiy SM, Baker PR, Freeman BA, Brookes PS. Mitochondrial nitroalkene formation and mild uncoupling in ischaemic preconditioning: implications for cardioprotection. Cardiovasc Res 2009; 82: 333-340, doi: 10.1093/cvr/cvn323.

15. Tsikas D, Zoerner AA, Mitschke A, Gutzki FM. Nitro-fatty acids occur in human plasma in the picomolar range: a targeted nitro-lipidomics GC-MS/MS study. Lipids 2009; 44: 855-865, doi: 10.1007/s11745-009-3332-4.

16. Schopfer FJ, Batthyany C, Baker PR, Bonacci G, Cole MP, Rudolph $\mathrm{V}$, et al. Detection and quantification of protein adduction by electrophilic fatty acids: mitochondrial generation of fatty acid nitroalkene derivatives. Free Radic Biol Med 2009; 46: 1250-1259, doi: 10.1016/j.freeradbiomed. 2008.12.025

17. Salvemini D, Seibert K, Masferrer JL, Settle SL, Currie MG, Needleman P. Nitric oxide activates the cyclooxygenase pathway in inflammation. Am J Ther 1995; 2: 616-619, doi: 10.1097/00045391-199509000-00007.

18. Trostchansky A, Souza JM, Ferreira A, Ferrari M, Blanco F, Trujillo $M$, et al. Synthesis, isomer characterization, and anti-inflammatory properties of nitroarachidonate. Biochemistry 2007; 46: 4645-4653, doi: 10.1021/bi602652j.

19. Blanco F, Ferreira AM, Lopez GV, Bonilla L, Gonzalez M, Cerecetto $\mathrm{H}$, et al. 6-Methylnitroarachidonate: a novel esterified nitroalkene that potently inhibits platelet aggregation 
and exerts cGMP-mediated vascular relaxation. Free Radic Biol Med 2011; 50: 411-418, doi: 10.1016/j.freeradbiomed. 2010.11.031.

20. Alexander RL, Bates DJ, Wright MW, King SB, Morrow CS. Modulation of nitrated lipid signaling by multidrug resistance protein 1 (MRP1): glutathione conjugation and MRP1-mediated efflux inhibit nitrolinoleic acid-induced, PPARgammadependent transcription activation. Biochemistry 2006; 45: 7889-7896, doi: 10.1021/bi0605639.

21. Baker LM, Baker PR, Golin-Bisello F, Schopfer FJ, Fink M, Woodcock SR, et al. Nitro-fatty acid reaction with glutathione and cysteine. Kinetic analysis of thiol alkylation by a Michael addition reaction. J Biol Chem 2007; 282: 3108531093, doi: 10.1074/jbc.M704085200.

22. Batthyany C, Schopfer FJ, Baker PR, Duran R, Baker LM, Huang $Y$, et al. Reversible post-translational modification of proteins by nitrated fatty acids in vivo. J Biol Chem 2006; 281: 20450-20463, doi: 10.1074/jbc.M602814200.

23. Schopfer FJ, Lin Y, Baker PR, Cui T, Garcia-Barrio M, Zhang J, et al. Nitrolinoleic acid: an endogenous peroxisome proliferator-activated receptor gamma ligand. Proc Natl Acad Sci U S A 2005; 102: 2340-2345, doi: 10.1073/ pnas.0408384102.

24. Li Y, Zhang J, Schopfer FJ, Martynowski D, Garcia-Barrio MT, Kovach A, et al. Molecular recognition of nitrated fatty acids by PPAR gamma. Nat Struct Mol Biol 2008; 15: 865867, doi: 10.1038/nsmb.1447.

25. Villacorta L, Schopfer FJ, Zhang J, Freeman BA, Chen YE. PPARgamma and its ligands: therapeutic implications in cardiovascular disease. Clin Sci 2009; 116: 205-218, doi: 10.1042/CS20080195.

26. Wright MM, Schopfer FJ, Baker PR, Vidyasagar V, Powell $\mathrm{P}$, Chumley $\mathrm{P}$, et al. Fatty acid transduction of nitric oxide signaling: nitrolinoleic acid potently activates endothelial heme oxygenase 1 expression. Proc Natl Acad Sci U S A 2006; 103: 4299-4304, doi: 10.1073/pnas.0506541103.

27. Hong F, Sekhar KR, Freeman ML, Liebler DC. Specific patterns of electrophile adduction trigger Keap1 ubiquitination and Nrf2 activation. J Biol Chem 2005; 280: 3176831775, doi: 10.1074/jbc.M503346200.

28. Gao L, Wang J, Sekhar KR, Yin H, Yared NF, Schneider $\mathrm{SN}$, et al. Novel n-3 fatty acid oxidation products activate Nrf2 by destabilizing the association between Keap1 and Cullin3. J Biol Chem 2007; 282: 2529-2537, doi: 10.1074/ jbc.M607622200.

29. Dinkova-Kostova AT, Holtzclaw WD, Cole RN, Itoh K, Wakabayashi N, Katoh $\mathrm{Y}$, et al. Direct evidence that sulfhydryl groups of Keap1 are the sensors regulating induction of phase 2 enzymes that protect against carcinogens and oxidants. Proc Natl Acad Sci U S A 2002; 99: 11908-11913, doi: 10.1073/pnas.172398899.

30. Yamamoto T, Suzuki T, Kobayashi A, Wakabayashi J, Maher J, Motohashi $\mathrm{H}$, et al. Physiological significance of reactive cysteine residues of Keap1 in determining Nrf2 activity. Mol Cell Biol 2008; 28: 2758-2770, doi: 10.1128/ MCB.01704-07.

31. Eggler AL, Small E, Hannink M, Mesecar AD. Cul3mediated Nrf2 ubiquitination and antioxidant response element (ARE) activation are dependent on the partial molar volume at position 151 of Keap1. Biochem J 2009; 422: 171-180, doi: 10.1042/BJ20090471.
32. Li L, Kobayashi M, Kaneko H, Nakajima-Takagi $Y$, Nakayama Y, Yamamoto M. Molecular evolution of Keap1. Two Keap1 molecules with distinctive intervening region structures are conserved among fish. J Biol Chem 2008; 283: 3248-3255, doi: 10.1074/jbc.M708702200.

33. Kansanen E, Bonacci G, Schopfer FJ, Kuosmanen SM, Tong $\mathrm{KI}$, Leinonen $\mathrm{H}$, et al. Electrophilic nitro-fatty acids activate NRF2 by a KEAP1 cysteine 151-independent mechanism. J Biol Chem 2011; 286: 14019-14027, doi: 10.1074/jbc.M110.190710.

34. Villacorta L, Zhang J, Garcia-Barrio MT, Chen XL, Freeman BA, Chen YE, et al. Nitro-linoleic acid inhibits vascular smooth muscle cell proliferation via the Keap1/Nrf2 signaling pathway. Am J Physiol Heart Circ Physiol 2007; 293: H770-H776, doi: 10.1152/ajpheart.00261.2007.

35. Kansanen E, Jyrkkanen HK, Volger OL, Leinonen H, Kivela AM, Hakkinen SK, et al. Nrf2-dependent and -independent responses to nitro-fatty acids in human endothelial cells: identification of heat shock response as the major pathway activated by nitro-oleic acid. J Biol Chem 2009; 284: 3323333241, doi: 10.1074/jbc.M109.064873.

36. Marnett LJ, Rowlinson SW, Goodwin DC, Kalgutkar AS, Lanzo CA. Arachidonic acid oxygenation by COX-1 and COX-2. Mechanisms of catalysis and inhibition. J Biol Chem 1999; 274: 22903-22906, doi: 10.1074/jbc.274.33.22903.

37. Rouzer CA, Marnett LJ. Mechanism of free radical oxygenation of polyunsaturated fatty acids by cyclooxygenases. Chem Rev 2003; 103: 2239-2304, doi: 10.1021/ cr000068x.

38. van der Donk WA, Tsai AL, Kulmacz RJ. The cyclooxygenase reaction mechanism. Biochemistry 2002; 41: 1545115458, doi: 10.1021/bi026938h.

39. Malkowski MG, Ginell SL, Smith WL, Garavito RM. The productive conformation of arachidonic acid bound to prostaglandin synthase. Science 2000; 289: 1933-1937, doi: $10.1126 /$ science.289.5486.1933.

40. Smith WL, Song I. The enzymology of prostaglandin endoperoxide $\mathrm{H}$ synthases-1 and -2. Prostaglandins Other Lipid Mediat 2002; 68-69: 115-128, doi: 10.1016/S00906980(02)00025-4.

41. Trostchansky A, Bonilla L, Thomas CP, O'Donnell VB, Marnett LJ, Radi R, et al. Nitroarachidonic acid, a novel peroxidase inhibitor of prostaglandin endoperoxide $\mathrm{H}$ synthases 1 and 2. J Biol Chem 2011; 286: 12891-12900, doi: 10.1074/jbc.M110.154518.

42. Bonilla L, O'Donnell VB, Clark SR, Rubbo H, Trostchansky A. Regulation of protein kinase $C$ by nitroarachidonic acid: impact on human platelet activation. Arch Biochem Biophys 2013; 533: 55-61, doi: 10.1016/j.abb.2013.03.001.

43. Gonzalez-Perilli L, Alvarez MN, Prolo C, Radi R, Rubbo H, Trostchansky A. Nitroarachidonic acid prevents NADPH oxidase assembly and superoxide radical production in activated macrophages. Free Radic Biol Med 2013; 58: 126133, doi: 10.1016/j.freeradbiomed.2012.12.020.

44. Zhang J, Villacorta L, Chang L, Fan Z, Hamblin M, Zhu T, et al. Nitro-oleic acid inhibits angiotensin II-induced hypertension. Circ Res 2010; 107: 540-548, doi: 10.1161/CIRCRESAHA. 110.218404 .

45. Rudolph TK, Rudolph V, Edreira MM, Cole MP, Bonacci G, Schopfer FJ, et al. Nitro-fatty acids reduce atherosclerosis in apolipoprotein E-deficient mice. Arterioscler Thromb Vasc 
Biol 2010; 30: 938-945, doi: 10.1161/ATVBAHA.109. 201582.

46. Villacorta L, Chang L, Salvatore SR, Ichikawa T, Zhang J, Petrovic-Djergovic D, et al. Electrophilic nitro-fatty acids inhibit vascular inflammation by disrupting LPS-dependent
TLR4 signalling in lipid rafts. Cardiovasc Res 2013; 98: 116124, doi: $10.1093 /$ cvr/cvt002.

47. Rubbo H, Radi R. Protein and lipid nitration: role in redox signaling and injury. Biochim Biophys Acta 2008; 1780: 1318-1324, doi: 10.1016/j.bbagen.2008.03.007. 